\title{
http://revistainvestigacionacademicasinfrontera.com
}

Recibido el 28 de marzo de 2018. Dictaminado mediante arbitraje favorablemente 31 de agosto de 2018

\section{Estructura categorial exploratoria de la movilización civil en la construcción de una agenda de seguridad}

\section{Exploratory category structure of civil mobilization in the construction of a security agenda}

\author{
Silvia Mejía-Rubio, Abigail Quezada-Castro, Adriana Vanessa Blanes-Ugarte, Jessica \\ Coss-Guerrero, Griselda Pérez-Hernández, María Luisa Quintero-Soto, Rosa María \\ Rincón-Ornelas, Cruz García Lirios
}

\begin{abstract}
Resumen -La construcción de una agenda en relación con la movilización civil en torno a la seguridad es un abordaje nuevo en el sentido teórico por la simbiosis entre los fenómenos y empírico por la observación de esas relaciones en la literatura consultada. El objetivo del trabajo fue establecer una estructura de categorías y subcategorías para observar las posibles relaciones orientadas a la contrastación de un modelo factorial. Se realizó un estudio documental con una selección intencional de fuentes indexadas a repositorios internacionales, considerando un periodo de diez años, así como la búsqueda por palabras claves. Se encontró una prevalencia del establecimiento de la agenda en relación a la seguridad y la movilización.
\end{abstract}

Palabras claves: medios de comunicación, agenda, modelo, participación, identidad

\begin{abstract}
The construction of an agenda in relation to civil mobilization around security is a new approach in the theoretical sense for the symbiosis between the phenomena and empirical observation of those relationships in the literature consulted. The objective of the work was to establish a structure of categories and subcategories to observe the possible
\end{abstract}


Año 11.

Revista de Investigación

Núm. 28

Académica sin Frontera

ISSN: 2007-8870

\section{http://revistainvestigacionacademicasinfrontera.com}

relations oriented to the contrast of a factorial model. A documentary study was carried out with an intentional selection of sources indexed to international repositories, considering a period of ten years, as well as the search for keywords. A prevalence of setting the agenda was found in relation to security and mobilization.

Keywords -media, agenda, model, participation, identity

\section{Introducción}

El objetivo del presente trabajo es establecer una estructura de categorías y subcategorías relativas a la participación, esencialmente en su fase de movilización ante la edificación de una agenda de seguridad común a los actores políticos y civiles, así como a los sectores públicos y privados.

En el marco de la gobernanza de la seguridad pública, la construcción de la agenda agenda mediante los mecanismos de inclusión y participación social supone una identidad que subyace luego de que la información es procesada por redes sociales y diseminada en opinión e iniciativas civiles a través de los medios de comunicación (García, Rivera y Aguilar, 2018).

La participación entendida como efecto de la privación social y causa de identidad, movilización, elección, opinión, sufragio, innovación y emprendimiento emerge relaciones asimétricas entre gobernantes y gobernados. En la era digital asumida como el acceso a información diseminada en agendas públicas y temas de discusión parece reducir a su mínima expresión a la participación ya que ésta requiere de libertades de expresión que las redes sociales minimizan a opiniones (Sharples, 2010).

El binomio Internet y opinión es producto de la transformación del Estado en tanto que las políticas públicas, programas sociales o accionar gubernamental son evaluadas por internautas en función de tendencias diseminadas por los medios de comunicación 


\section{http://revistainvestigacionacademicasinfrontera.com}

tradicionales como la televisión, la radio, el cine o la prensa como es el caso de líderes de opiniones o comunicadores con altos niveles de expectación (Carreón, Blanes y García, 2018).

Es así como la participación en la era digital no sólo remite al impacto de los medios en la construcción de una democracia participativa y deliberativa, sino además implica el establecimiento de una agenda a partir de los temas diseminados en televisión, radio o prensa, pero ya no sólo en función de los niveles de expectación sino a partir de la construcción de ejes y temas de discusión que demandan la inclusión de la sociedad civil en la estructura de las instituciones de seguridad (Aldana, Rosas y García, 2018).

La agenda ciudadana, resultado de la difusión de los medios, está implicada con la acción colectiva y la movilización ciudadana en tanto que ambas son producto de las creencias informativas que las audiencias procesan de dos modos; central o racional y periférico o emocional. En el primer caso, se asume que la ciudadanía en tanto audiencias tiene grados de necesidades de buscar información que se ajuste a sus razonamientos. En el segundo caso, las audiencias buscan información que se ajuste a sus emociones (Carreón, García y Blanes, 2018).

En la era digital de las Tecnologías de Información y Comunicación, Internet y redes digitales, los razonamientos y emociones son sustituidos por percepciones de utilidad, facilidad, eficacia y control. Es decir, ayer la ciudadanía se hacinaba en las plazas públicas, hoy satura los servidores digitales o páginas electrónicas siguiendo dos lógicas: verosimilitud y verificabilidad (Martínez, Anguiano y García, 2018).

La percepción de utilidad derivada de la lógica de verosimilitud identifica información consistente con discursos mediáticos que atribuyen al Estado la pérdida de su rectoría y 


\section{http://revistainvestigacionacademicasinfrontera.com}

legitiman la privatización de los servicios públicos como el de la seguridad, la prevención del delito y la misma impartición de justicia (García, Carreón y Hernández, 2018).

Este es el caso de la televisión que supone su financiamiento a partir del nivel de expectación y la cotización subsecuente de anuncios orientados a la legitimación de la violencia intrafamiliar como lo destacan los mensajes de atribución de liderazgo a los hombres en detrimento de los derechos de las mujeres. Son los medios de comunicación los que exhiben los desaciertos de la clase política y generan percepciones de inseguridad, incertidumbre, riesgo, miedo o indignación en sus audiencias, estableciendo los ejes y temas de discusión en una agenda orientada a la influencia de la opinión civil y la legitimación de políticas, estrategias y programas de seguridad centrados en la violencia del Estado (Alboreida, Carreón, Mejía y García, 2018).

Es el caso del combate a la delincuencia mediante la formación de efectivos y cuerpos de seguridad, inversión en tecnología de vigilancia y espionaje a líderes políticos, sociales o civiles con la finalidad de legitimar pesquisas sin considerar los derechos humanos elementales como el de libre asociación o libertad de expresión (Quintero, Hernández, Sánchez, Molina y García, 2018).

En contraste, la percepción de utilidad, derivada de la lógica de verificabilidad supone la producción de contenidos o diseminación de información hacia audiencias con altos niveles de instrucción habituados a contrastar los acontecimientos con reportajes, columnas, noticias, o entrevistas con expertos (Carreón, Hernández y García, 2018).

La lógica de verosimilitud evidencia la corrupción, negligencia, opacidad, nepotismo o cooptación del Estado ante las problemáticas económicas, políticas o sociales. La lógica de verificabilidad supone el contraste de los hechos presentados en los medios que inciden en 


\section{http://revistainvestigacionacademicasinfrontera.com}

demandas de desregulación del Estado a fin de poder tener mayores opciones de elección (Carreón, Hernández y García, 2017).

Las dos lógicas, verificabilidad y verosimilitud, se intensifican a medida que la necesidad de información aumenta, pero una reducción en la expectación o audiencia genera emociones más que razonamientos. En virtud de que las emociones están relacionadas con decisiones imprevistas, la ciudadanía no desarrolla percepciones de utilidad, sino más bien de incertidumbre, inseguridad o riesgo. Sin embargo, las percepciones de utilidad no son exclusivas de razonamientos dado que por sí solos éstos son insuficientes ante tecnologías o dispositivos electrónicos que se perciben como inaccesibles, dificultosos o complejos (García, Sandoval y Aguilar, 2016).

La relación entre sociedad y Estado se disemina en todas las relaciones de poder entre instituciones y ciudadanos, funcionarios y usuarios, autoridades y civiles. Internet es un anexo de las relaciones asimétricas entre gobernantes y gobernados. Es en la red en donde las fuerzas de seguridad vigilan a internautas a fin de poder garantizar la seguridad digital, pública y nacional (García, Carreón y Hernández, 2016).

Del mismo modo que en los espacios públicos la policía se encarga del control de riesgos, la ciberpolicía en Internet tiene la función de procurar justicia y anticipar movilizaciones que afecten la estabilidad social y la paz pública. La agenda cibernética, se construye con los mismos actores con los que se construye la agenda pública. Los medios de comunicación, en el caso de Internet las redes sociales, diseminan temas de discusión hasta llegar a acuerdos que en el caso de la red son condenas públicas, ridiculizaciones de políticos, exhibición de la corrupción, demandas de justicia o propuestas de inconformidad (Mejía, Carreón y García, 2016). 


\section{http://revistainvestigacionacademicasinfrontera.com}

Si la agenda pública forma opiniones ciudadanas, la agenda cibernética forma opiniones twiteras, wahtsaperas o faceboleras desde los que es posible inferir acciones o movilizaciones digitales como es el caso de la difusión de eventos que se consideran injustos, corruptos o delictivos (Carreón, García, Vilchis, Martínez, Sánchez y Quintana, 2016).

Es posible anticipar escenarios tales como; 1) el control de la cibered por parte del Estado bajo el argumento de la seguridad nacional y el combate al terrorismo cuyos efectos podrán ser observados en la reducción de suscriptores y usuarios de las redes sociales, así como la movilización para restaurar los derechos de información, privacidad y expresión, 2) la desregulación de Internet como resultado de los avances tecnológicos y el advenimiento de innovaciones que determinarán costos significativos a las instituciones más que ganancias o utilidades relativas al control (García, Carreón y Hernández, 2015).

La relevancia de las TIC's e Internet estriba en el monto de inversión que los gobiernos han gestionado para evidenciar el grado de desarrollo nacional o regional como es el caso de la difusión de la ciencia y la tecnología en repositorios, revistas o páginas institucionales, ministeriales o académicas (García, 2015).

La Organización para Cooperación y el Desarrollo Económico (OCDE) devela que los montos de inversión en infraestructura de telecomunicaciones han aumentado en los últimos diez años. La inversión en tecnologías, dispositivos y redes electrónicas del conocimiento se ha intensificado, la suscripción a la banda ancha refleja el progreso tecnológico de Islandía y Corea del Sur, así como la crisis de Grecia o República Eslovaquia. La suscripción a la televisión de pago muestra el avance de Bélgica o Suiza, pero también el retroceso de Turquía. El acceso a Internet por vía de la suscripción que en el caso de los Estados Unidos con respecto a Islandia refleja diferencias significativas entre el país con mayor número de suscriptores y el país con el menor número de solicitudes. 


\section{http://revistainvestigacionacademicasinfrontera.com}

La agenda internauta está presente tanto en aquellas economías desarrolladas como en países emergentes. A medida que se intensifica la regulación de Internet, inhibe las oportunidades y capacidades. En contraste, una reducción de la inversión y suscripción incentiva el emprendimiento y la innovación, pero el aumento de estos rubros disemina temas que configuran una agenda pública y con ello subyace la participación de internautas (Viera, 2013).

El equilibrio entre seguridad, identidad, equidad y justicia devela relaciones asimétricas entre gobernantes y gobernados desde los que el poder es un patrimonio de quienes dialogan, debaten y acuerdan establecer como temas centrales de debate a la regulación o desregulación de los medios de comunicación y el uso de TICs. De este modo, la construcción de una agenda supone el análisis de la participación que en el caso de las redes sociales de Internet conllevan una identidad opuesta a la que se gesta en los espacios públicos dado que la ciudadanía adopta diferentes estilos de participación según el escenario, contexto y situación en el que se le ubique (Buelvas, y Amaris, 2010).

Libertad, seguridad y justicia suponen oportunidades y capacidades desde el Estado hacia la ciudadanía, pero el resultado de la interrelación entre estos factores supuso cuando menos tres identidades; apolítica, subpolítica y política. La identidad apolítica es producto de la pérdida de rectoría del Estado y por consiguiente la ausencia de garantías de seguridad pública que culminarán con percepciones de injusticia, incertidumbre, riesgo o inseguridad (García, 2011). La identidad subpolítica, la emergencia de grupos disidentes explica no sólo la ingobernabilidad, sino el advenimiento de conflictos entre gobernantes y gobernados ante el autoritarismo del Estado (Carreón, 2013).

A diferencia de los sistemas totalitarios en los que los regímenes contaban con fuerzas coercitivas, las democracias cuentan con fuerzas persuasivas tales como medios de comunicación (García 2013). A medida que los temas se establecían desde el Estado para el 


\section{http://revistainvestigacionacademicasinfrontera.com}

control de la ciudadanía, ésta último desarrolló redes de participación, pero la falta de una agenda pública exacerbó los autoritarismos y totalitarismos.

Los autoritarismos suponen no sólo la intensificación de la seguridad territorial, sino la exacerbación del poder del régimen ante las demandas de libertad, oportunidad y justicia (García, 2014). Los regímenes autoritarios son producto de la restricción de libertades, pero no necesariamente se manifiestan en la coerción de la disidencia, ya que el uso de propaganda nacionalista supone la unión de identidades ante una amenaza común, pero en su mayoría la junta militar o el gobierno civil auto-impuesto inhiben el debate y la contienda política que restaure o cuando menos oriente la elección de un nuevo sistema político (Carreón, 2014).

La elección a partir del contraste de ideas se gesta en los medios de comunicación una vez que los temas de discusión sobrepasaron a los grupos debatientes y se expanden a los sectores marginados, pero la propaganda difundida en la prensa por parte de los regímenes autoritarios resultó ser un ensayo preliminar con respecto al impacto de la televisión o Internet en la opinión ciudadana (García, 2013).

La estructura de las democracias, parlamentarias, semi-presidenciales y presidenciales supone el debate y contienda necesarios para la elección de un ministro, presidente o grupo que a partir de estrategias persuasivas incidirá en simpatizantes adherentes o incluso disidentes una vez que el anterior gobierno ha sido desvinculado de la identidad que los electores quieren asumir (Carreón, 2014). La censura en el sistema parlamentario y el veto en el presidencialista son instrumentos de gestión del voto que no sólo garantizan el equilibrio de poderes por contrapesos, sino además abren la agenda a temas provenientes de la ciudadanía misma que a su vez es influenciada por los medios de comunicación (García, 2011). 


\section{http://revistainvestigacionacademicasinfrontera.com}

Las audiencias de la televisión, radio, prensa y cine al orientarse a las redes sociales como Facebook o Twitter abren la discusión en torno al establecimiento de temas a partir de la información disponible en estas tecnologías. Incluso, son los medios de comunicación tradicionales quienes retoman las opiniones de los usuarios de redes sociales para establecer los temas en la agenda ciudadana y la agenda política (Carreón y Hernández, 2015).

Los estudios relativos a la participación se han centrado en la explicación de emociones ciudadanas hacia sus gobernantes (Carreón, 2013), la complejidad de las instituciones políticas y civiles (Carreón, 2014), el sistema político coercitivo y persuasivo (García, 2011), la violencia (García, 2013), la propaganda (García, 2014), la hegemonía de los medios de comunicación sobre la opinión ciudadana (Quiroga, 2013), la libertad informativa (Viera, 2013) y la ciudadanización de la migración (Pac y Migijón, 2011).

\section{Método}

Se llevó a cabo un estudio no experimental, documental, retrospectivo y exploratorio con una selección no probabilística e intencional de fuentes indexadas a repositorios internacionales líderes de los ejes y temáticas de la investigación como Dialnet, Latindex, Publindex, Redalyc y Scielo, considerando el periodo de 2010 a 2018, así como la búsqueda por palabras claves: "seguridad”, “agenda" y "movilización” (véase Tabla 1).

Tabla 1. Descriptivos de la muestra informativa

\begin{tabular}{cccc}
\hline & Seguridad & Agenda & Movilización \\
\hline Dialnet & 45 & 32 & 27 \\
\hline Latindex & 37 & 25 & 14 \\
\hline Publindex & 26 & 16 & 9 \\
\hline Redalyc & 19 & 10 & 5 \\
\hline Scielo & 8 & 4 & 2 \\
\hline
\end{tabular}

Fuente: Elaborada con los datos del estudio 


\section{http://revistainvestigacionacademicasinfrontera.com}

Se construyó una matriz de análisis de contenido a partir de la técnica Delphi: 1) síntesis de contenidos, 2) contextualización de información, 3) comparación de datos y 4) integración de elementos. jueces expertos en las temáticas calificaron los extractos a partir de -1 para memorandos desfavorable, 0 para información desvinculada, +1 para datos favorables (véase Tabla 2).

Tabla 2. Construcción de la matriz de datos

\begin{tabular}{|c|c|c|c|c|}
\hline & Definición & Indicación & Codificación & Interpretación \\
\hline Seguridad & $\begin{array}{l}\text { Refiere al Estado de } \\
\text { derecho (García, 2011) }\end{array}$ & $\begin{array}{l}\text { Datos sobre la } \\
\text { prevención del delito y } \\
\text { la impartición de } \\
\text { justicia (García, 2015) }\end{array}$ & $\begin{array}{l}\text {-1 para memorandos } \\
\text { desfavorable, } 0 \text { para } \\
\text { información } \\
\text { desvinculada, +1 para } \\
\text { datos favorables }\end{array}$ & $\begin{array}{l}\text { Altos puntajes sugieren } \\
\text { un sistema de seguridad } \\
\text { centrado en } \\
\text { prevención del delito y } \\
\text { la impartición de } \\
\text { justicia }\end{array}$ \\
\hline Agenda & $\begin{array}{l}\text { Sugiere la construcción } \\
\text { de ejes y temas de } \\
\text { discusión pública } \\
\text { (García, 2013) }\end{array}$ & $\begin{array}{l}\text { Datos acerca de } \\
\text { desencuentros } \\
\text { acuerdos entre actores } \\
\text { políticos y sociales, así } \\
\text { como entre sectores } \\
\text { públicos y privados } \\
\text { (García, 2016) }\end{array}$ & $\begin{array}{l}\text {-1 para memorandos } \\
\text { desfavorable, 0 para } \\
\text { información } \\
\text { desvinculada, +1 para } \\
\text { datos favorables }\end{array}$ & $\begin{array}{l}\text { Atos puntajes aluden a } \\
\text { la construcción de una } \\
\text { agenda centrada en } \\
\text { acuerdos políticos y } \\
\text { sociales }\end{array}$ \\
\hline Movilización & $\begin{array}{l}\text { Alude a una respuesta } \\
\text { civil ante los casos de } \\
\text { corrupción político } \\
\text { (García, 2014) }\end{array}$ & $\begin{array}{l}\text { Datos acerca de } \\
\text { impunidad, negligencia, } \\
\text { opacidad, colusión, } \\
\text { nepotismo, cooptación o } \\
\text { soborno (Carreón, } \\
\text { 2013). }\end{array}$ & $\begin{array}{l}\text {-1 para memorandos } \\
\text { desfavorable, 0 para } \\
\text { información } \\
\text { desvinculada, +1 para } \\
\text { datos favorables }\end{array}$ & $\begin{array}{l}\text { Altos puntajes suponen } \\
\text { una movilización } \\
\text { sustentada en altos } \\
\text { niveles de impunidad, } \\
\text { negligencia, opacidad, } \\
\text { nepotismo, cooptación, } \\
\text { soborno o colusión }\end{array}$ \\
\hline
\end{tabular}

Fuente: Elaboración propia

La información fue procesada en el paquete de análisis cualitativo de datos (QDA-MINNER por su acrónimo en inglés versión 4,0). 
Año 11.

Revista de Investigación

Núm. 28

Académica sin Frontera

ISSN: 2007-8870

\section{http://revistainvestigacionacademicasinfrontera.com}

Se construyó una teoría y se contrastó con los estudios más recientes en torno a la temática. Posteriormente, se elaboró un modelo y se discutió sus alcances y límites en el marco de las Tecnologías de Información y Comunicación, la democratización del Estado y sus instituciones. El contraste de las ocho hipótesis incluidas en el modelo permitirá no sólo anticipar escenarios de conflicto entre gobernantes y gobernados ante la seguridad y sustentabilidad, sino además contribuirá con el esclarecimiento de la reproducción de temas establecidos en los medios de comunicación, las asimetrías entre ciudadanía y Estado, o bien, el papel de los medios de comunicación tradicionales como televisión, prensa y radio frente a la influencia de Internet en la evaluación de políticas públicas.

\section{Resultados}

La Tabla 3 muestra los descriptivos de la construcción de la matriz de análisis de contenido. Es posible apreciar e inferir la prevalencia de tres categorías con respecto a once subcategorías.

Tabla 3. Descriptivos de la matriz de datos

\begin{tabular}{|c|c|c|c|c|c|c|c|}
\hline & $\mathbf{M}$ & D & $\mathbf{A}$ & $\mathbf{C}$ & Seguridad C1 & Agenda (C2) & Movilización (C3) \\
\hline Acuerdos (S1) & ,956 & ,193 & ,133 & ,126 & $\left\lceil\mathrm{X}^{2}=15,2(12 \mathrm{gl}) \mathrm{p}<, 01\right\}$ & & \\
\hline Prevención (S2) & ,978 &, 123 & ,112 &, 130 & $\left\lceil\mathrm{X}^{2}=14,1(12 \mathrm{gl}) \mathrm{p}<, 01\right\}$ & & \\
\hline Colusión (S3) & ,906 & ,193 & ,189 &, 146 & & $\left\{\mathrm{X}^{2}=14,1(14 \mathrm{gl}) \mathrm{p}<, 01\right\}$ & \\
\hline Cooptación (S4) & ,925 & ,135 & ,175 & ,136 & & $\left\lceil\mathrm{X}^{2}=14,1(15 \mathrm{gl}) \mathrm{p}<, 01\right\}$ & \\
\hline Impunidad (S5) & ,902 &, 120 & ,142 &, 157 & & $\left\lceil\mathrm{X}^{2}=17,1(19 \mathrm{gl}) \mathrm{p}<, 01\right\}$ & \\
\hline Justicia (S6) & ,983 &, 134 &, 135 &, 123 & & $\left\lceil X^{2}=172,(13 \mathrm{gl}) \mathrm{p}<, 01\right\}$ & \\
\hline Negligencia (S7) & ,951 & , 145 & ,156 & ,178 & & $\left\{\mathrm{X}^{2}=12,1(18 \mathrm{gl}) \mathrm{p}<, 01\right\}$ & \\
\hline Nepotismo (S8) & ,931 &, 126 & ,190 &, 143 & & $\left\lceil\mathrm{X}^{2}=19,1(10 \mathrm{gl}) \mathrm{p}<, 01\right\}$ & \\
\hline Opacidad (S9) & ,904 &, 173 &, 167 &, 183 & & $\left\lceil\mathrm{X}^{2}=15,1(18 \mathrm{gl}) \mathrm{p}<, 01\right\}$ & \\
\hline Soborno (S10) & ,961 &, 121 & ,153 &, 165 & & $\left\{\mathrm{X}^{2}=181,(18 \mathrm{gl}) \mathrm{p}<, 01\right\}$ & \\
\hline Desencuentros (S11) & ,971 & ,159 & ,123 &, 135 & & & $\left\lceil\mathrm{X}^{2}=15,1(13 \mathrm{gl}) \mathrm{p}<, 01\right\}$ \\
\hline
\end{tabular}


Año 11.

Revista de Investigación

Núm. 28

Académica sin Frontera

ISSN: 2007-8870

\section{http://revistainvestigacionacademicasinfrontera.com}

$\mathrm{S}=$ Subcategoría, $\mathrm{M}=$ Media, $\mathrm{D}=$ Desviación Estándar, $\mathrm{A}=$ Asimetría, $\mathrm{C}=$ Curtosis, $\mathrm{C}=$ Categoría

Fuente: Elaborada con los datos del estudio

Una vez establecidos las relaciones contingentes entre las categorías y las subcategorías se procedió a estimar y a observar su estructura (véase Figura 1).

Figura 1. Estructura categorial exploratoria

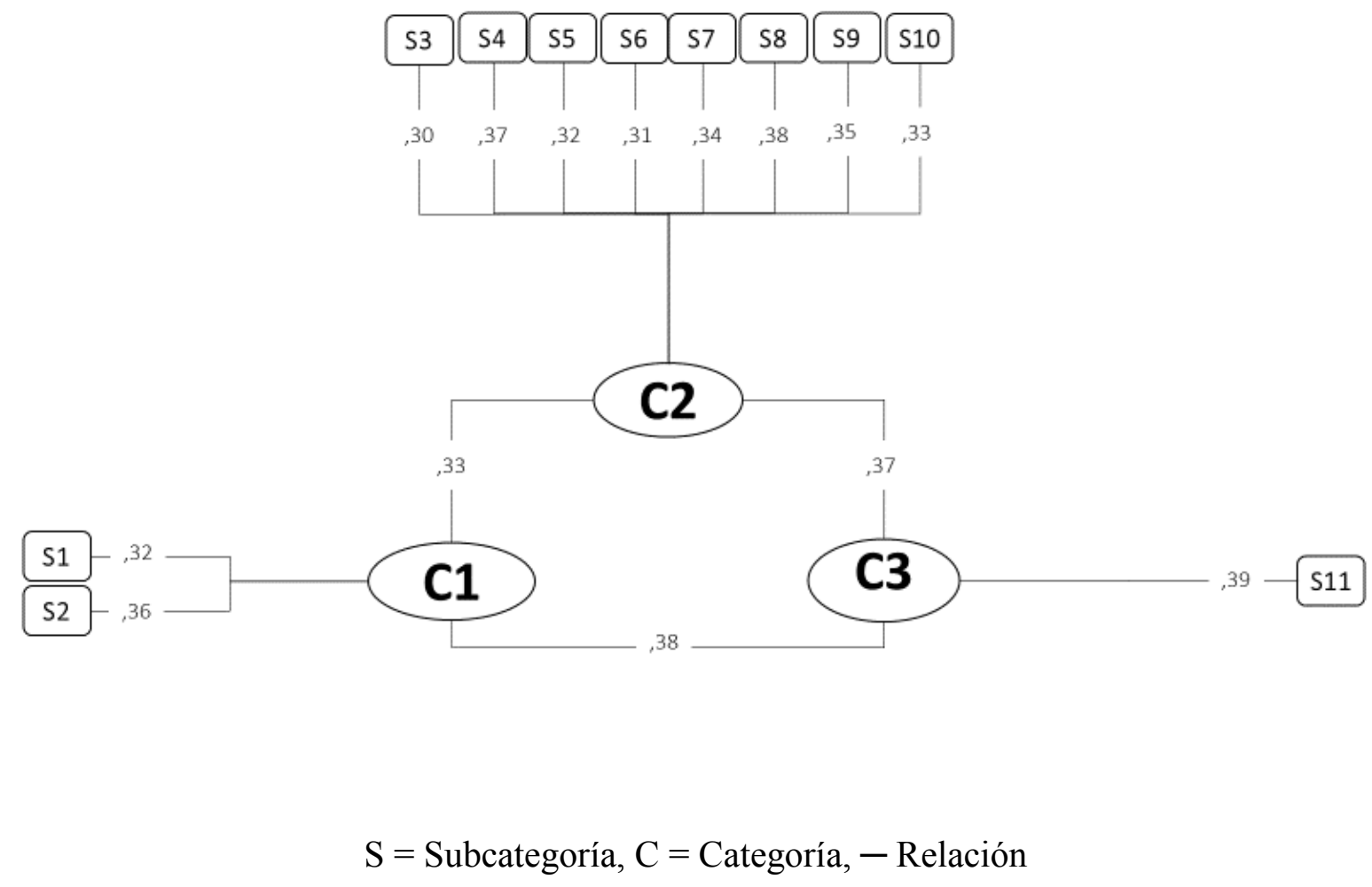

Fuente: Elaborada con los datos del estudio

En el marco de la democratización del Estado y la rendición de cuentas el acceso a la información es fundamental para esclarecer la transparencia en la toma de decisiones. Las 


\section{http://revistainvestigacionacademicasinfrontera.com}

redes influyen en los usuarios de Facebook o Twitter, pero éstos mismos diseminan la información mediante sus opiniones en otros grupos.

No obstante, la información no es del todo procesada y por ello la selección de contenidos, imágenes y frases es menester ante la inconmensurabilidad de símbolos y significados que se difunden en Internet. Por ello, el establecimiento de temas supone una refinación de mensajes debido a que subyace una lógica de verosimilitud que se contrasta con las opiniones disponibles.

La compatibilidad entre la información accesible y seleccionada explica el seguimiento de nodos informativos en la red y el establecimiento de agendas en las redes sociales. La compatibilidad es producto de la influencia que ejercen los usuarios en sus contactos. Resultado del procesamiento de información, la necesidad de obtener más detalles genera razonamientos a partir de discursos, o bien, en el caso de las imágenes propicia más afectos vinculados con los contactos.

Si la información genera razonamientos que por su grado de procesamiento suponen una persuasión más prolongada que las imágenes y afectos correspondientes, entonces los acuerdos serán resultado del debate informativo más que de la reproducción de información generada en las redes sociales. Una vez que la información es procesada en razonamientos y utilizada para su contraste, el consenso antecede a la responsabilidad que implica no sólo la observación y seguimiento ciudadano de iniciativas, sino la gestión del conocimiento que garantice el emprendimiento y la innovación de temas para su inserción en la agenda pública.

El emprendimiento supone la búsqueda, selección, asimilación, discusión, consenso y difusión de información a fin de poder establecer temas en la agenda de las redes sociales, aunque las imágenes que generan afectos pueden derivar en el emprendimiento de creaciones y la expresividad de emociones. En virtud de que una innovación es producto de información 


\section{http://revistainvestigacionacademicasinfrontera.com}

arraigada en forma de creencias y percepciones de utilidad, una fase posterior al emprendimiento informativo es la producción de información que se distingue de la reproducción al momento de establecer los temas emitidos por una red en la agenda pública, las iniciativas políticas y la opinión ciudadana.

La reproducción de información que se explica en el nivel de acceso, selección, compatibilidad, acumulación, consenso, responsabilidad y emprendimiento supone la propaganda del Estado diseminada en los medios de comunicación y dispositivos tecnológicos mediante razonamientos o afectos que permiten la discusión de temas incuestionables por ser considerados como imprescindibles para la paz pública y la inclusión de grupos vulnerables, marginados o excluidos que permitan el crecimiento económico o el bienestar social.

La producción de conocimiento, resultado de la reproducción de información concerniente a temas de la agenda pública establecida, evidencia la emisión de temas que parten de la ciudadanía, se infiltran en los medios y orientan las políticas públicas en función de su grado de innovación.

\section{Consideraciones finales}

El presente trabajo ha expuesto la estructura de categorías y subcategorías de la movilización civil para mostrar su importancia en la construcción de una agenda que permita discutir los temas críticos de la seguridad. En referencia a las revisiones y propuestas de Carreón (2014) y García (2014) en los que la seguridad pública es un tema central en el establecimiento de una agenda pública, el presente escrito propone que estos temas son transformados por los medios de comunicación en discursos e imágenes que generan razonamientos y afectos a partir de los cuales la información concerniente es procesada de un modo tal que reproduce 


\section{http://revistainvestigacionacademicasinfrontera.com}

la agenda establecida por los medios, aunque ello implique conformidad también genera innovación.

Esto es así porque las redes sociales están generando temas que los mismos medios retoman para construir su agenda y diseminarla en la opinión ciudadana, la evaluación de políticas y la generación de iniciativas de ley. Es por ello que resulta fundamental el contraste de la estructura de categorías y subcategorías a fin de poder explicar el establecimiento de temas desde las redes sociales.

Sin embargo, es posible advertir que el establecimiento de una agenda no significa la discusión de los temas difundidos, sino más bien la reproducción de creencias, actitudes, percepciones, decisiones y acciones en Internet de la misma forma que en otros espacios públicos o privados. Sólo en el caso de la producción de conocimiento será posible observar la construcción de una agenda desde temas relativos a la seguridad, así como las asimetrías entre gobernantes y gobernados.

El estudio de este proceso de producción de conocimiento anticipará escenarios de conflictos entre autoridades y ciudadanos respecto a los servicios públicos. El aporte del presente trabajo al estudio de la agenda y participación ciudadana en redes sociales de Internet estriba en la especificación de relaciones entre categorías y subcategorías de un modelo. La estructura no sólo explica la construcción de una agenda, sino además plantean el contraste de las relaciones como evidencia de emergencia de una agenda entrada en las categorías y subcategorías de estudio.

\section{Referencias}

Alboreida, D., Carreón, J., Mejía, S. y García, C. (2018). Especificación de un modelo de representaciones propagandísticas en adultos mayores ante la seguridad pública. Tlatemoani, 25, 1-10 


\section{http://revistainvestigacionacademicasinfrontera.com}

Aldana, W. I., Rosas, F. J. y García, C. (2018). Especificación de un modelo para el estudio de la seguridad pública. Atlante, 9, 1-20

Buelvas, F. y Amaris, M. (2010). Comprensión del bienestar de una persona desplazada por la violencia sociopolítica. Psicología desde el Caribe, 26, 156-177

Carreón, J. (2013). Emociones de inseguridad determinantes de la desconfianza hacia las autoridades. Revista de Psicología Política, 11 (31), 52-62

Carreón, J. (2014). Complejidad sociopolítica del transporte público. Tlatemoani, 15, 1-22

Carreón, J. García, C. y Blanes, A. V. (2018). Redes de violencia en torno a la gobernanza de la seguridad pública. Ciencias Sociales, 4 (2), 60-65

Carreón, J. y Hernández, J. (2015). Teorías para explicar el origen, construcción y establecimiento de la agenda sociopolítica. Vivat Academia, 23 (130), 109-137

Carreón, J., Blanes, A. V. y García, C. (2018). Confiabilidad y validez de un modelo de gobernanza percibida de la inseguridad. Sin frontera, 11 (27), 1-43

Carreón, J., García, C., Vilchis, F. J., Martínez, J., Sánchez, R. y Quintana, L. D. (2016). Confiabilidad y validez de un instrumento que mide siete dimensiones de la percepción de seguridad en estudiantes de una universidad pública. Pensando Psicología, 12 (20), 65-76 http://dx.doi.org/10.16925/pe.v12i20.1564

Carreón, J., Hernández, J. y García, C. (2017). Agenda pública y participación sociopolítica. Fermentum, 75 (26), 41-56

Carreón, J., Hernández, J. y García, C. (2018). Una revisión teórica para el estudio de la gobernanza de la seguridad pública. Gepu, 4, 1-15

García, C. (2011). Una aproximación sistémica a la realidad política. Enfoques, 23 (1), 6378

García, C. (2013). Sistemas de violencia sociopolítica. Polis, 12 (36), 343-365

García, C. (2014). Sistemas sociopsicológicos de la propaganda. Enseñanza e Investigación, 19 (1), 219-244

García, C. (2015). Gobernanza de la delincuencia sociopolítica en México. Documentos, Reflexión y Análisis, 14, 47-69 


\section{http://revistainvestigacionacademicasinfrontera.com}

García, C. (2016). La legitimidad de la administración de seguridad pública en Xilitla, San Luis Potosí, México. Investigación Administrativa, 115 (44), 24-40

García, C., Carreón, J. y Hernández, J. (2015). Gobernanza de la seguridad pública a partir de la identidad y percepción de riesgo establecidos en la agenda ciudadana por los medios de comunicación. Rumbos, 11 (13), 103-116

García, C., Carreón, J. y Hernández, J. (2016). Gobernanza del terror a la delincuencia. Eureka, 13 (2), 168-185

García, C., Carreón, J. y Hernández, J. (2018). Gobernanza de la seguridad pública. Revisión de la literatura para una discusión del estado del conocimiento de la identidad sociopolítica delictiva. $84,1-17$

García, C., Rivera, A. G. y Aguilar, J. A. (2018). Encuadre de redes digitales en torno a valores millennials en los sismos del 7S y 19S. Tlatemoani, 27, 1-22

García, C., Sandoval, F. R. y Aguilar, J. A. (2016). Aproximación al encuadre de los medios impresos en torno a la atención a víctimas del caso Ayotzinapa, Iguala-Guerrero (México). Seeci, 20 (39), 153-160

Hosseini, H. (2010). Activism knowledge: interrogating the ideational landscape of social movements. International Journal of Interdisciplinary Social Science, 5, 339-357

Martínez, F., Anguiano, F. y García, C. (2018). Governance of social work towards a network violence. Social Science Learning Educational Journal, 3 (6), 1-3

Mejía, S., Carreón, J. y García, C. (2016). Efectos psicológicos de la violencia e inseguridad en adultos mayores. Eureka, 13 (1), 39-55

Pac, D. y Mingijón, J. (2011). Percepción ciudadana de la participación sociopolítica. RIPS, $10(2), 117-129$

Quintero, M. L., Hernández, T. J., Sánchez, A., Molina, H. D. y García, C. (2018). Modelo de expectativas en torno a la seguridad pública en microempresarios del centro de México. Investigación Académica Sin frontera, 10 (26), 1-20

Quiroga, M. (2013). Perspectivas para el análisis de la acción colectiva: Algunas reflexiones críticas y posibles aportes a la Teoría de la Hegemonía. Araucaria Revista de Filosofía, Política y Humanidades, 15, 25-44 
Núm. 28

ISSN: 2007-8870

\title{
http://revistainvestigacionacademicasinfrontera.com
}

Sharples, D. (2010). Communicating climate science: evaluating the UK public's attitude to climate change. Earth and Environment, 5, 185-205

Viera, E. (2013). Construyendo psicología política latinoamericana desde la psicología de la liberación. Revista de Psicología Política, 11 (30), 37-56

\begin{abstract}
Para citar este artículo
Silvia Mejía-Rubio, Abigail Quezada-Castro, Adriana Vanessa BlanesUgarte, Jessica Coss-Guerrero, Griselda Pérez-Hernández, María Luisa Quintero-Soto, Rosa María Rincón-Ornelas, Cruz García Lirios. Estructura categorial exploratoria de la movilización civil en la construcción de una agenda de seguridad. RIASF. Núm. 28, Julio-diciembre (2018), ISSN 2007-8870. pp. $\mathrm{xx}-\mathrm{xx}$.
\end{abstract}

